\title{
Intragastric gastric band migration: erosion: an analysis of multicenter experience on 177 patients
}

\author{
Nicola Di Lorenzo • Michele Lorenzo • Francesco Furbetta • Franco Favretti • \\ Cristiano Giardiello $\cdot$ Sergio Boschi - Genco Alfredo - Giancarlo Micheletto • \\ Vincenzo Borrelli • Augusto Veneziani - Marcello Lucchese • Marcello Boni · \\ Simona Civitelli • Ida Camperchioli • Vincenzo Pilone • Maurizio De Luca • \\ Paolo De Meis • Massimiliano Cipriano • Michele Paganelli • Vincenzo Mancuso • \\ Angelo Gardinazzi · Angelo Schettino · Roberta Maselli $\cdot$ Pietro Forestieri
}

Received: 25 April 2012/ Accepted: 23 August 2012/Published online: 17 October 2012

(C) Springer Science+Business Media, LLC 2012

\begin{abstract}
Background Laparoscopic adjustable gastric banding (LAGB) has proven to be a safe and effective surgical treatment for morbid obesity. It can be a simple, fast, reversible, anatomy-preserving procedure. Despite these advantages, its long-term efficacy came into question by the occurrence of complications such as intragastric band migration. Consistent information regarding this complication is still lacking. Treatment for migration is still being debated as well. Most of the inconsistencies of these data stem from the very low number of patients reported in single-center experiences or case reports. Lack of multicenter experience is evident. The aim of this study was to perform a retrospective analysis of data on intragastric migration in a large multicenter cohort of patients who underwent LAGB.

Methods A retrospective multicenter study on LAGB patients was performed. Data had been entered into a prospective database of the Italian Group for LapBand ${ }^{\circledR}$ (GILB) since January 1997. Pars flaccida and perigastric positioning were considered along with different kinds of gastric bands by the same manufacturer. Time of diagnosis, mean body mass index (BMI), presentation symptoms, and
\end{abstract}

N. Di Lorenzo · M. Lorenzo · F. Furbetta · F. Favretti ·

C. Giardiello · S. Boschi - G. Alfredo - G. Micheletto ·

V. Borrelli · A. Veneziani - M. Lucchese - M. Boni ·

S. Civitelli · I. Camperchioli · V. Pilone - M. De Luca ·

P. De Meis · M. Cipriano - M. Paganelli · V. Mancuso ·

A. Gardinazzi - A. Schettino - R. Maselli · P. Forestieri

Italian Group for LapBand, Città della Scienza, Naples, Italy

M. Lorenzo $(\square)$

Via Maresca 54, 80058 Torre Annunziata, NA, Italy

e-mail: michele.lorenzo@gmail.com conservative and surgical therapy of intragastric migration were considered.

Results From January 1997 to December 2009, a total of 6,839 patients underwent LAGB and their data were recorded [5,660 females, 1,179 males; mean age $38.5 \pm 18.2$ years (range 21-62 years); mean BMI $=46.7 \pm 7.7 \mathrm{~kg} / \mathrm{m}^{2}$ (range 37.3-68.3); excess weight (EW) $61.8 \pm 25.4 \mathrm{~kg}$ (range 36-130); \%EW $91.1 \pm 32.4 \%$ (range 21-112\%)]. A total of 177 of $6,839(2.5 \%)$ intragastric erosions were observed. According to the postoperative time of followup, the diagnosis of intragastric migration was made in 74 (41.8\%), 14 (7.9\%), 38 (21.4\%), 40 (22.6\%), 6 (3.4\%), and $4(2.2 \%)$ banded patients at $6-12,24,36,48,60$, and 72 months after banding, respectively. Most of intragastric band migration during the first 2 years occurred in bands with no or a few milliliters of filling. In patients with late erosion, the bands were adjusted several times; no band was overfilled but one was filled to the maximum or submaximum with a maximum of two adjustments. Erosions diagnosed during the first 24 months were related to the experience of the surgical staff, while late erosions were not.

Conclusions Intragastric band migration or band erosion is a rare, disturbing, and usually not life-threatening complication of gastric banding. Its pathogenesis is probably linked to different mechanisms in early (technical failure in retrogastric passage) or late (band management) presentation. It is usually asymptomatic and there is no pathognomonic presentation. A wide range of therapeutic options are available, from simple endoscopic or laparoscopic removal to early or late band replacement or other bariatric procedure. More experience and more studies are needed to lower its presentation rate and definitively clarify its pathogenesis to address the right therapeutic option. 
Keywords Laparoscopic adjustable gastric band . Bariatric surgery · Obesity

Laparoscopic adjustable gastric banding (LAGB) has proven to be a safe and effective surgical treatment for morbid obesity. LAGB, in the hands of an experienced surgeon, can be a simple, fast, reversible, anatomy-preserving procedure. For this reason it is nowadays one of the most popular techniques for the surgical treatment of obesity [1-3]. Despite these advantages, its long-term efficacy has come into question because of complications such as gastric pouch dilation and intragastric band migration directly linked to the erosion of the gastric wall caused by the prosthesis [4-6].

The use of prosthetic devices around the stomach is not a new concept: different materials such as silicone, Silastic $^{\circledR}$, Marlex ${ }^{\circledR}$, Dacron, and Gore-Tex were used for different surgical approaches. One of the complications of these prosthetic devices is intragastric migration, usually called band migration [7-10]. Symptoms associated with intragastric band migration are retrograde port infection, loss of satiety, and stop of weight loss. Consistent information regarding intragastric migration is still lacking and there is considerable controversy about the still unclear incidence rate and etiology [1, 11-13]. The treatment for these complications is still being debated as well. Most of the inconsistencies of these data stem from the very low number of patients reported in single-center experiences or case reports. Lack of multicenter experience is evident.

The aim of this study was to perform a retrospective analysis of data on intragastric migration in a large multicenter cohort of patients who underwent LAGB.

\section{Patients and Methods}

A retrospective multicenter study on LAGB patients was performed. Data were entered into the prospective database of the Italian Group for LapBand ${ }^{\circledR}$ (GILB) starting in January 1999. Also in this database are data of patients operated on since January 1997. Surgeons who are members of GILB have to enter into the database all data about patients who are in follow-up also if they were operated on in other centers.

\section{Band Positioning}

Different kinds of gastric bands produced by Allergan (Irvine, CA, USA) were used in these patients. Bands were implanted by a pars flaccida or a perigastric route with the patient in an anti-Trendelenburg position; antibiotics and antithrombotic prophylaxis were given [14]. Until 1997 the vast majority of centers whose patients participated in this study used the perigastric approach, while after 2005 almost all moved to the pars flaccida route.

\section{Laparoscopic Band Removal}

Laparoscopic removal of the migrated intragastric band usually starts with identifying the connecting tube, separating it from the port, and eventually freeing omental adhesions. The band is cut in the esogastric portion, gently pulled out, and removed, making sure that the band ring is complete. In case of partial ring migration, a short (4-6 cm) longitudinal anterior gastrotomy can be performed immediately below the position of the band. The band is grasped, divided, and pulled out. The gastrotomy is then closed with various techniques.

\section{Endoscopic Band Removal}

The first step in endoscopic band removal is the identification of the inner part of the partially migrated band. The band is not removed if the migration is less than $50 \%$ and if the lock has also not migrated. In these cases, a "watch and wait" period is suggested. The residual gastric bridge over the band is not removed to avoid gastric perforation or fistulas. The metallic thread of a gastric band cutter is inserted into the operative channel of the endoscope. The metallic thread is passed around the band and then inserted into a metal tube external arrow connected to and handgrip with tourniquet. By turning the handgrip the band is strangulated and broken into sections by the metal loop under direct vision. Then the band is freed from the gastric wall bridge and from the connecting port tube and is gently extracted with a polypectomy loop.

Statistical Analysis

Data from our experiences were expressed as mean \pm standard deviation (SD), except when otherwise indicated. Statistical analysis was done by means of Student's $t$ test or $\chi^{2}$ test or Fisher's exact test, and $p<0.05$ was considered significant.

\section{Results}

From January 1997 to December 2009, a total of 6,839 patients underwent laparoscopic adjustable gastric banding with devices produced by Allergan (Table 1). The patients' data were entered into the database of the Italian Group for LapBand [5,660 females, 1,179 males; mean age $=38.5 \pm$ 18.2 years (range $21-62$ ); mean $\mathrm{BMI}=46.7 \pm 7.7 \mathrm{~kg} / \mathrm{m}^{2}$ (37.3-68.3); excess weight loss (EW) $61.8 \pm 25.4 \mathrm{~kg}$ 
Table 1 Basic characteristics of a gastric band: size, positioning, and maximum filling volume according to manufacturer's indications

\begin{tabular}{lll}
\hline Band & Band positioning & $\begin{array}{c}\text { Maximum } \\
\text { filling }(\mathrm{ml})\end{array}$ \\
\hline $9.75 \mathrm{~cm}$ & Perigastric & 4 \\
$10 \mathrm{~cm}$ & Perigastric & 4 \\
$11 \mathrm{~cm}$ & Pars flaccida & 9 \\
AP small & Pars flaccida & 10 \\
VG & Pars flaccida & 11 \\
AP large & Pars flaccida & 14 \\
\hline
\end{tabular}

(36-130); \%EW $91.1 \pm 32.4 \%(21-112)]$. The overall percentage of follow-up was $75.8 \%$ and all data were inserted into the database. A total of 177 (2.5\%) intragastric erosions were observed. According to the postoperative time of follow-up, the diagnosis of intragastric migration was made in $74(41.8 \%), 14(7.9 \%), 38$ $(21.4 \%), 40(22.6 \%), 6(3.4 \%)$, and $4(2.2 \%)$ banded patients at $6-12,24,36,48,60$, and 72 months after banding, respectively (Fig. 1). During the first 6-12 months all kinds of bands were used, most of which $(53 / 74 ; 71.6 \%)$ were positioned via the perigastric route. In the later erosions $(79 / 103 ; 76.7 \%)$, the perigastricplaced $9.75-\mathrm{cm}$ band was prevalent (Table 2). At 6-12month follow-up, erosions were diagnosed in 32/74 $(43.2 \%)$ by port-system infection, in $15 / 74(20.3 \%)$ by intractable digestive symptoms, and 27/74 (36.5\%) were asymptomatic. Almost all (90/103; $87.4 \%)$ late erosions were asymptomatic and diagnosed by routine follow-up exams during band adjustment. The differences in clinical presentation between the early- and late-diagnosis groups are reported in Table 2. The erosion site was reported in 147 of the $177(83.0 \%)$ cases and it corresponds to the left posterior gastric wall without peritoneum.

Most of intragastric band migration that occurred during the first 2 years involved bands with no or a few milliliters of filling. In patients with late erosion, the band was adjusted several times. No band was overfilled, but one was filled to the maximum or submaximum with a maximum of two adjustments.

The relationship between early erosions and the surgical skill of the operator was confirmed by the learning curve diagram (Fig. 2). Erosions diagnosed during the first 24 months were related to the experience of the surgical staff $(p<0.001)$, while late erosions were independent of $(\mathrm{p}=\mathrm{ns})$.

Follow-up of patients with intragastric migration was complete. Patients seen or operated on for this complication in different centers where the band was placed were also entered into the database. Early in the study period, diagnosed erosion was treated by immediate laparotomic band removal. With increasing experience, the laparoscopic approach was preferred, and in the later part of the study period, endoscopic removal gained wide consensus in many centers of the GILB. During the initial experience with this complication, the gastric band was removed immediately after diagnosis. In the following years, if patients continued to lose weight and/or the band was not completely migrated into the stomach, a "watch and wait" period was assumed (Table 3). After recovery from the removal procedure, a new bariatric procedure was performed in 24/65 patients.

The band was removed in 165/177 (93.2\%) patients with intragastric erosion, and the remaining 12 are still under clinical observation. The gastric band was removed via laparotomy, laparoscopy, or endoscopy in 44 (27.7\%), $69(41.8 \%)$ and $52(31.5 \%)$ patients, respectively. There was no mortality. The conversion rate to laparotomy in patients who underwent the laparoscopic approach was $2 / 88$ (2.3\%); the conversion was due to anatomosurgical problems. Conversion to a laparoscopic approach during endoscopic removal was $6 / 50(12 \%)$ and due to band cutter failure $(n=4)$ or connecting tube adhesions $(n=2)$. In $2 / 3(66.6 \%)$ patients in which the remnant gastric bridge over the port was sectioned, a gastric fistula developed. This complication was successfully resolved with endoscopy.
Fig. 1 Intragastric migration according to follow-up presentation

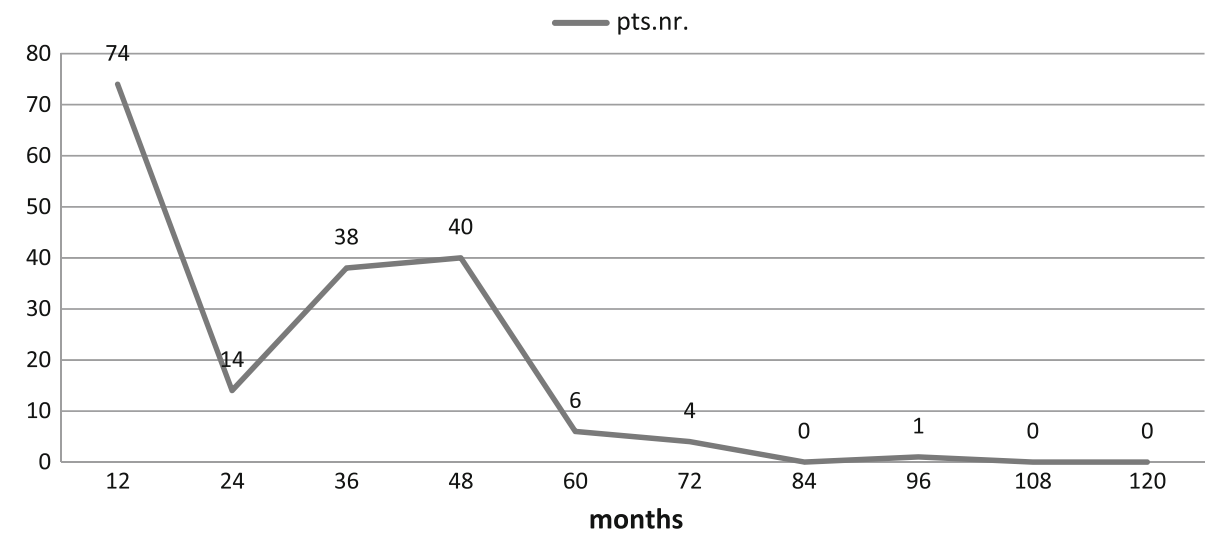


Table 2 Kind of band involved in intragastric migration and clinical presentation according to months of diagnosis after band positioning

\begin{tabular}{|c|c|c|c|}
\hline Months & No. patients & $\begin{array}{l}\text { Kind of } \\
\text { band involved }\end{array}$ & Clinical presentation $[n(\%)]$ \\
\hline $6-12$ & 69 & All & $\begin{array}{l}\text { Port infection: } 32(46.4)^{\circ} \\
\text { Asymptomatic : } 15(21.7)^{\mathrm{a}} \\
\text { Digestive symptoms: } 22(32.9) \\
\text { Satiety loss: } 7 \text { (10.1) }\end{array}$ \\
\hline $13-24$ & 16 & All & $\begin{array}{l}\text { Asymptomatic: } 9 \text { (56.2) } \\
\text { Digestive symptoms: } 7 \text { (43.8) } \\
\text { Satiety loss: } 2(12.4)\end{array}$ \\
\hline $25-36$ & 33 & $9.75,10,11, \mathrm{VG}$ & $\begin{array}{l}\text { Asymptomatic: } 21 \text { (63.6) } \\
\text { Digestive Symptoms: } 11 \text { (33.4) } \\
\text { Port infection: } 1(3.0) \\
\text { Satiety loss: } 2 \text { (6.0) }\end{array}$ \\
\hline $37-48$ & 34 & $9.75,10,11$ & $\begin{array}{l}\text { Asymptomatic: } 24(70.6)^{\mathrm{b}} \\
\text { Digestive Symptoms: } 9(26.5) \\
\text { Port infection: } 1(2.9) \\
\text { Satiety loss: } 2(5.8)\end{array}$ \\
\hline $49-60$ & 5 & $9.75,10, \mathrm{VG}$ & Asymptomatic \\
\hline $61-72$ & 4 & 9.75 & Asymptomatic \\
\hline $85-96$ & 1 & 9.75 & Asymptomatic \\
\hline
\end{tabular}

${ }^{a}$ Significantly lower

$(p<0.001)$ with respect to 3

and 4 years of follow-up presentations

${ }^{b}$ Significantly higher

$(p<0.001)$ with respect to the other follow-up presentations reported. Vertruyen and Paul [16] observed 10/727 (1.4 \%) patients with intragastric migration on the posterior gastric wall at mean follow-up of 27 months (range 17-29). Niville et al. [17] described 10 patients with intragastric migration at the level of the gastrogastric suture on the left side of the stomach and which occurred between 14 and 25 months after band positioning. Kurian [18] reported erosion in $9 / 2,437(0.39 \%)$ primary procedures at $10-45$ months of follow-up. Christou and Efthimiou [19] reported six erosions observed during the first 18 months after surgery. Cherian et al. [6] reported presentation of erosion in 10/17 patients during the first year and only 2 after the second year from band positioning. These authors support the hypothesis that intragastric migration is multifactorial, suggesting a different etiology depending on the timing of complication: early erosion could be related to iatrogenic microinjuries at the time of band insertion, while a delayed appearance could be due to a combination of insults to the gastric serosa, including ischemia and foreign body reaction or high internal pressure as a result of ingestion of excessively large food boluses early after surgery. Abu Abeid et al. [20] hypothesized a different pathophysiology for early (6-12 months) and late (>12 months) intragastric band migration immediately below the esophagogastric junction. They concluded that early erosions could be linked to minor damage to the gastric wall at the time of surgery, while late erosions may be due to a slower destructive process that occurs over a long period of time, allowing for apparent self-healing of the gastric wall [20]. 
Table 3 Intragastric migration kind of treatment

\begin{tabular}{lllr}
\hline Procedure & Associated procedure & Associate delayed procedure & No. patients \\
\hline Laparotomic removal & & 40 \\
Laparotomic removal & RY gastric bypass & 5 \\
Laparotomic removal & Biliopancreatic diversion & 1 \\
Laparoscopic removal & & & 20 \\
Laparoscopic removal & Rebanding via pars flaccida & & 15 \\
Laparoscopic removal & & LRY gastric bypass & 5 \\
Endoscopic removal & & & 8 \\
None & Laparoscopic removal & 28 \\
None & Endoscopic removal & 42 \\
\hline
\end{tabular}

Basic considerations from our observation is that during the first 12-24 months after surgery all kind of bands were involved in migration. This indirectly indicates a surgical technical problem during the preparation of the retrogastric tunnel or the band passage or positioning. The relationship of band migration with the surgical procedure was also confirmed by the learning curve. Erosions diagnosed during the first 24 months were significantly $(p<0.001)$ related to the experience of the surgical staff. Late erosions were not related to staff experience (Fig. 2).

In the late erosions, the $\geq 10$-ml bands were rarely involved. It has to be stressed that in the later years of the study period, not only did the band position switch from perigastric to pars flaccida, but the bands themselves changed considerably from their initial shape. Manufacturers have progressively introduced modifications, one of which has been a larger band volume up to $10 \mathrm{ml}$. Fried [21] observed that high-pressure/low-volume bands provide major pressure per square units of gastric surface during food passage as compared to low-pressure/highvolume bands. This fact surely has something to do with the low incidence of late erosions, if it is not the only reason. In the present study, late erosions were observed in patients in whom the maximum or submaximum volume was reached in one or two adjustments, and in a patient who underwent a surgical procedure for port complication 6 months before erosion.

Clinical presentation of band migration varies. A lifethreatening event was rarely observed [22, 23]. Hypovolemic shock with massive upper gastrointestinal hemorrhage due to erosion into the celiac axis or in the left gastric artery has been reported, as well as small bowel obstruction due to intragastric band erosion [24-26]. In most cases, clinical symptoms are absent or mild and transient, and many authors agree that a pathognomonic manifestation of intragastric erosion is absent [1-6, 14].

Cherian et al. [6], in a study of 17 of 865 patients, indicated that the most common symptom was the epigastric pain $(61 \%)$ followed by "loss of weight loss" or weight regain $(55.6 \%)$ and by port-site or occult sepsis
(44\%). Less common presentations were dysphagia, hematemesis, and early satiety.

In most cases the diagnosis of migration was made when the band appeared incorrectly positioned during fluoroscopy which was performed for band adjustment [27]. In our experience, the majority of patients were asymptomatic (Table 2) and the erosion was diagnosed during follow-up. The loss of satiety was observed only in $7 \%$ of the patients, and more than $50 \%$ continued to lose weight, causing a dilemma for the surgeon of whether to remove the band in the absence of a life-threatening situation.

The treatment of this complication is still a matter of concern. At the time of the first observed intragastric band migration, the only treatment conceived was its laparotomic removal [28-31]. Without the restriction of the band, most patients regained weight and gastric bypass or biliopancreatic diversion or sleeve gastrectomy was proposed [29-32]. Some surgeons started to remove the band via laparoscopy and place another band during the same session or several weeks later [33-35]. Initially, This was done for intragastric migration of band positioned via the perigastric pathway; pars flaccida positioning was used for the second band. For an initial pars flaccida-placed eroded band that was removed, the second band was placed on the same pathway. Recently, Egberts et al. [2], based on a literature review, reported that the rate of re-erosion with this strategy was low, with weight loss maintained at the same rate as that of other bariatric procedures. During the same period, the endoscopic band removal technique was developed [13, 36-38]. The endoscopic technique implies that $50 \%$ or more of the band, together with its lock, had migrated into the gastric lumen. The presence of a mucosal bridge can cause very difficult band mobilization. When the gastric bridge is very thin, an alternative can be to inject a solution of adrenalin 1:10,000, then section with a needle cutter. This technique was used in three patients in this study, but it is no longer used because a gastric fistula developed in two of three patients [36]. During endoscopic removal in our study, the band was transected by a gastric band cutter and extracted with a polypectomy loop in $28 / 32$ 
$(87.8 \%)$ patients. Because of instrument failure or breakage, a laparoscopic conversion was done in 4 (12.2\%) patients. Nieto [13], using a similar technique for gastric bands from several manufacturers, observed that $4 / 82$ (5\%) of bands were transected without removal, and 19/82 (22.6\%) patients had a second endoscopy for total removal. O'Brien [39], commenting on the Nieto article, criticized the endoscopic removal technique as compared to laparoscopic removal because of its unclear cost/benefit ratio. In some case reports, the banding cutter was used without complications. In the present study, laparoscopic conversion was done in four cases in which the metallic thread broke in two near the tourniquet. This complication was not life-threatening.

A laser technique was described by Weiss et al. [40], who preferred to cut the sutures with endoscopic scissors and then burn through the silicone bridge of the closure site of the band with a laser. Other techniques have been described but their relevance was limited by the singlecenter provenance and limited number of patients [41].

\section{Conclusion}

Intragastric band migration or band erosion is a rare, disturbing, and usually not life-threatening complication of gastric banding. Its pathogenesis is linked to probably different mechanisms in early (technical failure in retrogastric passage) or late (band management) presentation. It is usually asymptomatic and there is no pathognomonic presentation. A wide range of therapeutic options are available, from simple endoscopic or laparoscopic removal to early or late band replacement or other bariatric procedures. More experience and more studies are needed to decrease the incidence rate and definitively clarify its pathogenesis to address the right treatment option.

Disclosures All authors declare to have no conflicts of interest or financial ties to disclose.

\section{References}

1. Carelli AM, Youn HA, Kurian MS, Ren CJ, Fielding GD (2010) Safety of the laparoscopic adjustable gastric banding: 7 years data from US center of excellence. Surg Endosc 24:1819-1823

2. Egberts K, Brown WA, O'Brien PE (2011) Systematic review of erosion after laparoscopic adjustable gastric banding. Obes Surg 21:1272-1279

3. Angrisani L, Furbetta F, Doldi SB, Italian Group for Lap-Band (GILB) (2003) The Lap Band adjustable gastric banding system: the Italian experience with 1863 patients operated on 6 years. Surg Endosc 17:409-412

4. Dargent J (2004) Surgical treatment of morbid obesity by adjustable gastric band: the case for a conservative strategy in the case of failure - a 9-year series. Obes Surg 14:986-990
5. Nocca D, Frering V, Gallix B, de Seguin des Hons C, Noe P, Pierredon Foulonge MB, Millat B, Fabre JM (2005) Migration of adjustable gastric banding from a cohort study of 4,236 patients. Surg Endosc 19:947-950

6. Cherian PT, Goussous G, Ashori F, Sigurdsson A (2010) Band erosion after laparoscopic gastric banding: a retrospective analysis of 865 patients over 5 years. Surg Endosc 24:2031-2038

7. Fobi M, Lee H, Igwe D, Felahy B, James E, Stanczyc M, Fobi N (2001) Band erosion: incidence, etiology, management and outcome after banded vertical gastric bypass. Obes Surg 11: 699-707

8. Deitel M (1990) Erosion of Marlex band and Silastic ring into the stomach after gastroplasty. Am J Gastroenterol 85:665-666

9. Osborne DR, Hobbs KE (1981) Dacron graft erosion of the duodenum: a complication of interposition mesocaval shunt operations. Br J Surg 68:483-484

10. Dutta S (2007) Prosthetic esophageal erosion after mesh hiatoplasty in a child removed by transabdominal endogastric surgery. J Pediatric Surg 42:252-256

11. Meir E, Van Baden M (1999) Adjustable silicone gastric banding and band erosion: Personal experience and hypotheses. Obes Surg 9:191-193

12. Ceelen W, Walder J, Cardon A, Van Renterghem K, Hesse U, El Malt M, Pattyn P (2003) Surgical treatment of severe obesity with a low-pressure adjustable gastric band: experimental data and clinical results in 625 patients. Ann Surg 237:10-16

13. Neto MP, Ramos AC, Campos JM, Murakami AH, Falcão M, Moura EH, Evangelista LF, Escalona A, Zundel N (2010) Endoscopic removal of eroded adjustable gastric band: lessons learned after 5 years and 78 cases. Surg Obes Relat Dis 6:423-427

14. Di Lorenzo N, Furbetta F, Favretti F et al (2010) Laparoscopic adjustable gastric banding via pars flaccida vs perigastric positioning: technique, complications and results on 2,549 patients. Surg Endosc 24:1519-1523

15. Westling A, Bjurling K, Ohrvall $M$ et al (1998) Siliconeadjustable gastric banding: disappointing results. Obes Surg 8: 467-474

16. Vertruyen M, Paul G (2003) 11-cm Lap-Band System placement after history of intragastric migration. Obes Surg 13:435-438

17. Niville E, Dams A, Vlasselaers J (2001) Lap-Band erosion: incidence and treatment. Obes Surg 11:744-747

18. Kurian M, Sultan S, Garg K, Youn H, Fielding F, Ren-Fielding C (2010) Evaluating gastric erosion in band management: an algorithm for stratification of risk. Surg Obes Rel Dis 6:386-389

19. Christou N, Efthimiou E (2009) Five-year outcomes of laparoscopic adjustable gastric banding and laparoscopic Roux-en-Y gastric bypass in a comprehensive bariatric surgery program in Canada. Can J Surg 52:E249-E258

20. Abu Abeid S, Szold A (2001) Laparoscopic management of LapBand erosion. Obes Surg 17:87-89

21. Fried M (2008) The current science of gastric banding: an overview of pressure-volume theory in band adjustments. Surg Obes Relat Dis 4(3 Suppl):S14-S21

22. Rao AR, Ramalingam G (2006) Exsanguinating hemorrhage following gastric erosion after laparoscopic adjustable gastric banding. Obes Surg 16:1675-1678

23. Campos J, Famos A, Galvao MN, Siqueira L, Evangelista LF, Ferraz A, Ferraz E (2007) Hypovolemic shock due to intragastric migration of an adjustable gastric band. Obes Surg 17:362-364

24. Iqbal M, Majunath S, Seenath M, Khan A (2008) Massive upper gastrointestinal hemorrhage: an unusual presentation after laparoscopic adjustable gastric banding due to erosion into the celiac axis. Obes Surg 18:759-760

25. Png KS, Rao J, Lim KH, Chia KH (2008) Lap-band causing left gastric artery erosion presenting with torrential hemorrhage. Obes Surg 18:1050-1052 
26. Egbeare DM, Myers AF, Lawrance RJ (2007) Small bowel obstruction secondary to intragastric erosion and migration of a gastric band. J Gastrointest Surg 17:983-984

27. Hainaux B, Agneessens E, Rubesova E et al (2005) Intragastric band erosion after laparoscopic adjustable gastric banding for morbid obesity: imaging characteristics of an underreported complication. AJR Am J Roentgenol 184:109-112

28. Ayloo S, Bueno R (2009) Band erosion: laparoscopic removal of lap-band. Surg Endosc 23:657-658

29. Angrisani L, Lorenzo M, Santoro T, Nicodemi O, Persico G, Tesauro B (1999) Videolaparoscopic treatment of gastric banding complications. Obes Surg 9:58-62

30. Kohn GP, Hansen CA, Gilhome RW, McHenry RC, Spilias DC, Hensman C (2012) Laparoscopic management of gastric band erosions: a 10-year series of 49 cases. Surg Endosc 26:541-545

31. Patel S, Eckstein J, Acholonu E, Abu-Jaish W, Szomstein S, Rosenthal RJ (2010) Reasons and outcomes of laparoscopic revisional surgery after laparoscopic adjustable gastric banding for morbid obesity. Surg Obes Relat Dis 6:391-398

32. Suter M, Giusti V, Héraief E et al (2004) Band erosion after laparoscopic gastric banding: occurrence and results after conversion to Roux-en-Y gastric bypass. Obes Surg 14:381-386

33. Abu-Abeid S, Bar-Zohar D, Sagie B, Klausner J (2005) Treatment of intragastric band migration following laparoscopic banding: safety and feasibility of simultaneous laparoscopic band removal and replacement. Obes Surg 15:849-852
34. Chisholm J, Kitan N, Toouli J, Kow L (2011) Gastric band erosion in 63 cases: endoscopic removal and rebanding evaluated. Obes Surg 21:1676-1681

35. Niville E, Dams A, Van der Speeten K, Verhelst H (2005) Results of lap rebanding procedures after Lap-Band removal for band erosion - a mid-term evaluation. Obes Surg 15:630-633

36. Iacopini F, Di Lorenzo N, Altorio F, Schurr MO, Scozzarro A (2010) Over-the-scope clip closure of two chronic fistulas after gastric band penetration. World J Gastroenterol 16:1665-1669

37. Galvao NMP, Ramos AC, Campos JM, Murakami AH, Falcao M et al (2010) Endoscopic removal of eroded adjustable gastric band: lessons learned after 5 years and 78 cases. Surg Obes Relat Dis 6:413-428

38. Regushi L, Groebli Y, Meyer JL, Walder J, Margalith D, Schneider R (2003) Gastroscopic removal of an adjustable gastric band after partial intragastric migration. Obes Surg 13:281-284

39. O'Brien P (2010) Comment on: Endoscopic removal of eroded adjustable gastric band: lessons learned after 5 years and 78 cases. Surg Obes Relat Dis 6:427-428

40. Weiss H, Nehoda H, Labeck B, Peer R, Aigner F (2000) Gastroscopic band removal after intragastric migration of adjustable gastric band: a new minimal invasive technique. Obes Surg 10:167-170

41. Cherian PT, Goussus G, Sigurdsson A (2009) Management of band erosion with omental plugging: case series from a 5-year laparoscopic gastric banding experience. Obes Surg 19:1409-1431 